\title{
Transseptal Suturing Reduce Patient Anxiety after Septoplasty Compared to Nasal Packing
}

\author{
Kamran Sari, ${ }^{1, *}$, Ali Irfan Gul', Yunus Kantekin ${ }^{1}$, Ozgul Karaaslan ${ }^{2}, Z_{\text {Zliha Kapusuz Gencer }}^{1}$
}

\author{
${ }^{1}$ Bozok University School of Medicine, Ear Nose \& Throat Department, Yozgat, Turkey \\ ${ }^{2}$ Bozok University School of Medicine, Psychiatry Department, Yozgat/Turkey \\ * Corresponding author: Bozok University School of Medicine, Adnan Menderes Street Number 190, Yozgat/Turkey; \\ e-mail: kamransari@gmail.com
}

Summary: Background: We measured postoperative anxiety in patients who underwent transseptal suturing or nasal packing after septoplasty. Materials and Methods: Transseptal suturing was performed on Group 1 patients and nasal splints with airway were placed after septoplasty in Group 2 patients. Postoperative 48-h anxiety levels of both groups were measured using the State-Trait Anxiety Inventory (STAI) clinical assessment scale, prior to removal of nasal packing in Group 2. Results: Transseptal suturing was performed after septoplasty in 28 patients and nasal packing in 34 patients. The State-Trait Anxiety Inventory clinical assessment state (STAI-S) and trait (STAI-T) instruments were used to measure postoperative anxiety. The STAI-S scores were found 35.00 in the transseptal suturing group and 43.8 in the nasal packing group; the difference was found significant $(\mathrm{p}<0.05)$. The STAI-T scores were found 42.6 in the transseptal suturing group and 45.7 in the nasal packing group; the difference was not found significant $(\mathrm{p}>0.05)$. The rate of minor hemorrhage was found $10.7 \%$ in Group 1 patients. Conclusions: Transseptal suturing is simple and reliable when performed after septoplasty. The technique is painless and comfortable, and reduces patient anxiety (compared to that associated with nasal packing) with only a minor increase in operating time and hemorrhage.

Keywords: Septoplasty; Nasal packing; Transseptal suturing;Aanxiety

\section{Introduction}

Nasal septum deviation is one of the most common disorders treated in Ear Nose \& Throat (ENT) clinics. Septoplasty is very common. Nasal packing is often applied after surgery, primarily to control bleeding, but also to stabilize the cartilaginous and bony skeleton of the nose (1). Nasal packs prevent septal hematoma after surgery. However, removal of nasal packs may be painful. Also, some complications are associated with nasal packing; these include mucosal injury, septal perforation, and eustachian tube dysfunction $(1,2)$. Rarely, sleep respiratory disturbances, reduced arterial oxygen saturation during sleep, and toxic shock syndrome, may develop $(3,4)$. Therefore, transseptal suturing has been developed as an alternative. An important advantage of such suturing is that the pain caused by nasal packing is eliminated. Also, respiration is not affected and suture removal is easy, reducing patient anxiety (5).

Anxiety disorders are very common psychiatric conditions, with a lifetime prevalence of about $17 \%$ (6) Both physical problems and environmental factors can induce anxiety. Surgery may increase anxiety levels either preoperatively or postoperatively.

We investigated postoperative anxiety levels in patients undergoing transseptal suturing or nasal packing after septoplasty.

\section{Materials and Methods}

This was a prospective cross-sectional study on 62 patients with nasal septum deviations. All patients were referred to our Department of Otorhinolaryngology, Head and Neck Surgery, between May 2014 and October 2015. Written informed consent was obtained from each patient and our local Ethics Committee approved the work. The study was performed in accordance with the ethical principles of the Declaration of Helsinki. Detailed ENT and physical examinations were performed on all patients. The exclusion criteria included concha bullosa, nasal polyps, and any additional nasal or paranasal pathology. Septoplasty was performed on all patients under general anesthesia. In septoplasty surgery hemitransfixion incision was performed. Deviated bone and cartilage parts were removed. L strut was left. All operations were performed by the same surgeon. Patients were randomly divided into two groups. Transseptal suturing was performed on Group 1 patients and nasal splints with airway were placed after septoplasty in Group 2 patients. During the transseptal suture method, the nasal septum was sutured using a 3/0 vicryl suture (Vicryl 3/0 absorbable suture, Sinorgmed $\AA$, Shandong, China). We placed four separate horizontal transseptal mattress sutures (Figure 1) $(7,8)$. All patients were followed-up after surgery. Postoperative 48-h anxiety levels of both groups were 


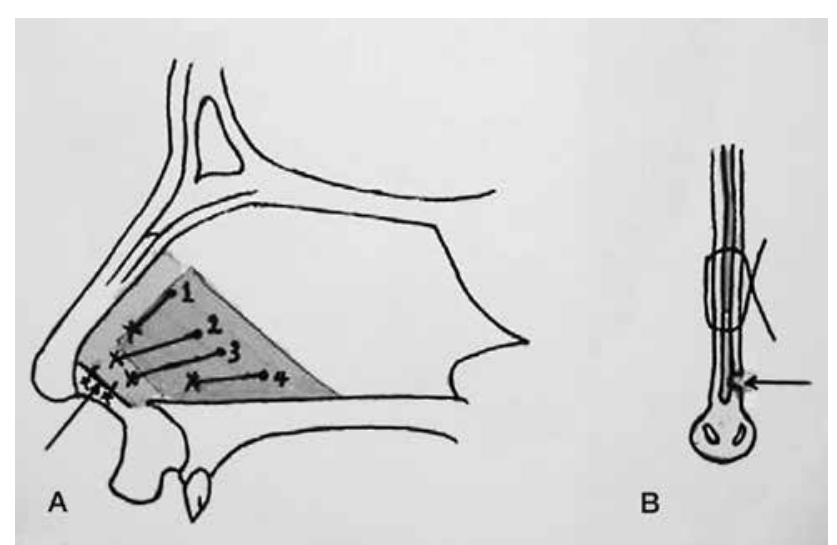

Fig. 1: Septal suturing technique. (A) Lateral view of the nose. The first suture is is inserted just below the dorsal part of the L-strut segment. This will act as a support especially when cartilage is removed from the dorsal part of the L-strut segment. (B) Axial view of the nose. It is demonstrated a separate through and through horizontal mattress suture passing through both sides of the septal mucuperichondrial flaps. Arrow, incision line; red area, removed area; yellow area, L-strut. (With the permission from Dr. Ardehali.)

measured using the State-Trait Anxiety Inventory (STAI) clinical assessment scale, prior to removal of nasal packing in Group 2.

\section{STAI (State-Trait Anxiety Inventory clinical assessment scale)}

The STAI was developed by Spielberger et al. (9) and measures state and trait anxiety in subjects $>14$ years of age of normal mental development. The STAI contains two forms: the STAI State (STAI-S) and STAI Trait (STAI-T).

The STAI-S measures the anxiety level at a specific time under certain conditions. In the state measure the participant was asked to answer "What degree do you feel at this moment?" Emotional state of each item has four response alternatives. These are "Not at all," "Somewhat," "Moderately so," and "Very much so". The STAI-T measures the anxiety level independent of the current conditions. In the trait measure, the participant was asked to answer "How often do you generally feel?" Each item has four response alternatives. "Almost never," "Sometimes," "Often," and "Almost always". Responses were scored by the Likert scoring method (i.e., 1-2-3-4). A higher score indicated a higher anxiety level (10). The STAI is simple, and is selfcompleted. Both forms can be completed at the same sitting. First, the STAI-S form is completed, followed by the STAIT. The Turkish version of the STAI questionnaire that we used has been validated in a Turkish population (11). Both the STAI-S and STAI-T responses are graded as follows: 1 (rarely); 2 (sometimes); 3 (a lot of the time); and 4 (almost always). The scores range from 20 to 80, and higher scores indicate more anxiety (12).

\section{Statistical analysis}

Anxiety levels were compared using SPSS for Windows software (ver. 18.0; SPSS Inc., Chicago, IL, USA). Descriptive data are presented as means and standard deviation (SD) for normally distributed variables. The normality of each variable was tested using the one-sample Kolmogorov-Smirnov test. No variable had a normal distribution. The chi-squared test was used to compare categorical variables between the groups. The Mann-Whitney U-test was used to evaluate between-group differences in continuous variables. A p-value $<0.05$ was considered to reflect statistical significance.

\section{Results}

The transseptal suturing group contained 28 patients (21 male, 7 female; mean age $=32.03 \pm 12.3$ years $)$ and the nasal packing group contained 34 patients (25 male, 9 female; mean age $=30.02 \pm 11.9$ years). Patient age did not differ significantly between the groups $(p=0.474)$. The STAI-S scores were $35.00 \pm 6.99$ in the transseptal suturing group and $43.8 \pm 13.9$ in the nasal packing group; the difference was significant $(\mathrm{p}=0.014)$. The STAI-T scores were $42.6 \pm 7.6$ in the transseptal suturing group and $45.7 \pm 11.7$ in the nasal packing group; the difference was not significant $(\mathrm{p}=0.335)$ (Table 1). The anxiety level did not differ by gender in either group (Table 2).

Tab. 1: The STAI-S-1 and STAI-S-2 scores of both groups.

\begin{tabular}{|l|c|c|c|c|c|}
\hline & Gender & Age & $\begin{array}{c}\text { STAI-S } \\
\text { Mean } \pm \text { SD }\end{array}$ & STAI-T & Surgical time \\
\hline Group1 $(\mathbf{n}=\mathbf{2 8})$ & Male 21, Female 7 & Mean 33.3 & $35.0 \pm 6.99$ & $42.6 \pm 7.6$ & $48.4 \pm 6.02 \mathrm{~min}$ \\
\hline Group 2 $(\mathbf{n}=\mathbf{3 4})$ & Male 25, Female 9 & Mean 30.01 & $43.8 \pm 13.9$ & $45.7 \pm 11.7$ & $41.8 \pm 5.9 \mathrm{~min}$ \\
\hline p value & & 0.474 & 0.024 & 0.335 & $<0.001$ \\
\hline Z value & & $-0.717^{*}$ & $-2.252^{*}$ & $-0.964^{*}$ & $-4.155^{*}$ \\
\hline
\end{tabular}

$\min =$ minute, $\mathrm{SD}$ (Standard Deviation)

*Mann-Whitney U Test 
Tab. 2: STAI-S and STAI-T scores by gender.

\begin{tabular}{|l|l|l|c|c|}
\hline \multirow{2}{*}{ Male } & & & STAI-S & STAI-T \\
\hline & $\begin{array}{l}\text { Transseptal } \\
\text { suture group }\end{array}$ & $\mathrm{n}=21$ & $35.7 \pm 10.6$ & $40.5 \pm 5.5$ \\
\cline { 2 - 5 } & $\begin{array}{l}\text { Nasal Pack } \\
\text { group }\end{array}$ & $\mathrm{n}=25$ & $41.8 \pm 14.2$ & $44.9 \pm 12.3$ \\
\hline p value & & & 0.145 & 0.400 \\
\hline Z value* & & & -1.458 & -0.842 \\
\hline \multirow{2}{*}{ Female } & $\begin{array}{l}\text { Transseptal } \\
\text { suture group }\end{array}$ & $\mathrm{n}=7$ & $37.0 \pm 8.6$ & $48.5 \pm 10.2$ \\
\cline { 2 - 5 } & $\begin{array}{l}\text { Nasal Pack } \\
\text { group }\end{array}$ & $\mathrm{n}=9$ & $49.3 \pm 12.4$ & $48.0 \pm 10.8$ \\
\hline p value & & & 0.060 & 0.832 \\
\hline Z value* & & & -1.882 & -0.213 \\
\hline
\end{tabular}

*Mann-Whitney U Test.

The mean surgical times were $48.4 \pm 6.02$ and $41.8 \pm 5.9 \mathrm{~min}$ in patients of Groups 1 and 2, respectively; the difference was significant $(\mathrm{p}<0.001)$.

One postoperative infection developed at the incision site of a Group 1 patient. Minor hemorrhage was observed in three Group 1 patients and was stopped successfully. No major hemorrhage, septal hematoma, perforation, or abscess was observed in either group postoperatively.

\section{Discussion}

Septoplasty is one of the most common nasal surgeries performed in otolaryngology clinics. Traditionally, nasal packing has been applied after septoplasty to control postoperative bleeding and stabilize the nasal septum. Many forms of nasal packing are available, including Merocel, "rapid rhino", the "Doyle pack", gauze with vaseline, and synthetic polyurethane. These are placed after surgery to prevent bleeding, septal hematoma, and septal abscess $(13,14)$. Although the packs afford many advantages, they increase the risk of infection and cause pain (15). Complications include eustachian tube dysfunction, middle ear effusion, and obstruction of the larynx. Also, $50-68 \%$ of the cilia of the surface mucosa may be functionally compromised by packing, and sinus infections can develop $(16,17)$. Packs can also cause mouth dryness and a sore throat. Aspiration and cardiological complications can also occur (1).

Removal of nasal packs causes serious pain, and can trigger significant patient anxiety. In recent years, transseptal suturing has been developed as an alternative to packing (18). Such suturing reduces patient pain and anxiety caused by respiratory problems and/or pack removal. Therefore, we compared the postoperative anxiety levels of patients with nasal packs (before pack removal) and those who underwent transseptal suturing. The STAI-S scores were lower in the transseptal suturing group than the nasal packing group $(p<0.05)$. However, the STAI-T scores were similar in the two groups. We suggest that this is because the STAI-T test evaluates general attitudes and feelings. We found that patients were anxious before removal of nasal packing. In addition not only decreased nasal breathing but also fear of packing removal can influence anxiety status in patients. Transseptal suturing may decrease postoperative pain and anxiety, improving the quality of life. Hosemann et al. (19) measured perioperative pain and anxiety levels in patients undergoing endoscopic sinus surgery, and compared three different types of nasal packing. Female gender, and detailed preoperative information on the surgical procedure, were associated with much more postoperative anxiety. For anxious patients, it was recommended that nasal packing should at least partially preserve nasal breathing. We found no significant association between gender and anxiety levels. Muluk et al. (20) tested the validity of Hospital Anxiety and Depression Scale (HADS) data from patients who underwent nasal surgery. They enrolled 50 adult patients who underwent nasal surgery for various reasons. Bilateral nasal packing was applied to all patients for 2 days. The anxiety and depression levels did not change significantly postoperatively. Thus, if patients were well-informed about nasal packing and hospital procedures prior to surgery, nasal packing was not associated with psychological trauma. It was observed that the HADS aided the diagnosis of emotional disorders, especially in patients who were hospitalized longterm. Rozanska-Kudelska et al. (21) studied the depression and anxiety symptoms of patients undergoing endoscopic sinus surgery, both before and after surgery. The levels of anxiety and depression were assessed using the Beck Depression Inventory (BDI) and the HADS. The BDI and HADS scores decreased significantly after surgery. It was claimed that high-quality treatment and improvement in somatic status enhanced the mental state and quality of life.

In all cited studies, anxiety and depression were measured both preoperatively and postoperatively. We did not apply the STAI preoperatively, because our aim was to measure the anxiety levels of patients just before removal of nasal packs and to compare these levels to those of patients without nasal packs.

The mean surgical time was somewhat longer in the transseptal suturing than the nasal packing group; the literature indicates that the mean surgical time was much longer previously $(7,8,22)$. A postoperative infection developed at the incision site of only one Group 1 patient, and responded to antibiotics. No postoperative septal hematoma, septal perforation, or major bleeding was observed in any patient.

The rate of minor hemorrhage has been reported as $2.3 \%$ in transseptal suturing septoplasty (23). In our study the rate was $10.7 \%$. Especially in the postoperative 24 hours minor hemorrhages are encountered frequent. These hemorrhages can be controlled with minor interventions, and usually no nasal packing is required. In our study no major hemorrhage, septal hematoma and septal perforation was encountered in any patient. 


\section{Conclusion}

Transseptal suturing is simple and reliable and can be safely performed after septoplasty. Although the operating time may increase slightly, the technique is painless and comfortable and reduces postoperative anxiety caused by nasal packing.

\section{References}

1. Ardehali MM, Bastaninejad S. Use of nasal packs and intranasal septal splints following septoplasty. Int J Oral Maxillofac Surg 2009; 38: 1022-24.

2. Thompson AC, Crowther JA. Effect of nasal packing on eustachian tube function. The J Laryngol Otol 1991; 105: 539-40.

3. Wagner R, Toback JM. Toxic shock syndrome following septoplasty using plastic septal splints. Laryngoscope 1986; 96: 609-10.

4. Yigit O, Cinar U, Uslu B, Akgul G, Topuz E, Dadas B. The effect of nasal packing with or without an airway on arterial blood gases during sleep. Kulak Burun Bogaz Ihtis Derg 2002; 9: 347-50.

5. Turhan M, Bostanci A, Akdag M, Dinc O. A comparison of the effects of packing or transseptal suture on polysomnographic parameters in septoplasty. Eur Arch Otorhinolaryngol 2013; 270: 1339-44.

6. Somers JM, Goldner EM, Waraich P, Hsu L. Prevalence and incidence studies of anxiety disorders: a systematic review of the literature. Can J Psychiatry 2006; 51 $100-13$.

7. Korkut AY, Teker AM, Eren SB, Gedikli O, Askiner O. A randomised prospective trial of trans-septal suturing using a novel device versus nasal packing for septoplasty. Rhinology 2010; 48: 179-82.

8. Lemmens W, Lemkens P. Septal suturing following nasal septoplasty, a valid alternative for nasal packing? Acta Otorhinolaryngol Belg 2001; 55: 215-21.

9. Spielberger CD GR, Lushene RE. Manuel for State-Trait Anxiety Inventory (Self-Evaluation Questionnaire). 2nd ed. California: Consulting Psychologists Press, 1970: 20-21

10. Iwata N, Mishima N, Shimizu T, et al. The Japanese adaptation of the STAI Form $\mathrm{Y}$ in Japanese working adults - the presence or absence of anxiety. Ind Health1998; 36: $8-13$.
11. AK Ö. Sürekli öfke (SL-Öfke) ve öfke ifade tarzı (Öfke tarz) ölçekleri ön çalışması. (Pre-evaluation of state and trait anxiety inventories). Türk Psikoloji Dergisi 1994; 9: 26-35.

12. Song QH, Xu RM, Zhang QH, Ma M, Zhao XP. Relaxation training during chemotherapy for breast cancer improves mental health and lessens adverse events. Int J Clin Exp Med 2013; 25: 979-84.

13. Hesham A, Ghali A. Rapid Rhino versus Merocel nasal packs in septal surgery. J Laryngol Otol 2011; 125: 1244-46.

14. Kim YS, Kim YH, Kim NH, Kim SH, Kim KR, Kim KS. A prospective, randomized, single-blinded controlled trial on biodegradable synthetic polyurethane foam as a packing material after septoplasty. Am J Rhinol Allergy 2011; 25: 77-9.

15. Banglawala SM, Gill M, Sommer DD, Psaltis A, Schlosser R, Gupta M. Is nasal packing necessary after septoplasty? A meta-analysis. Int Forum Allergy Rhinol 2013; 3: 418-24.

16. Abram AC, Bellian KT, Giles WJ, Gross CW. Toxic shock syndrome after functional endonasal sinus surgery: an all or none phenomenon? Laryngoscope 1994, 104: 927-31.

17. Shaw CL, Dymock RB, Cowin A, Wormald PJ. Effect of packing on nasal mucosa of sheep. J Laryngol Otol 2000; 114: 506-09.

18. Certal V, Silva H, Santos T, Correia A, Carvalho C. Trans-septal suturing technique in septoplasty: a systematic review and meta-analysis. Rhinology 2012; 50: $236-45$.

19. Hosemann W, Loew TH, Forster M, Kuhnel T, Beule AG. Perioperative pain and anxiety in endoscopic sinus surgery. Laryngorhinootologie 2011; 90: 476-80.

20. Muluk NB, Oguzturk O, Ekici A, Koc C. Emotional effects of nasal packing measured by the Hospital Anxiety and Depression Scale in patients following nasal surgery. J Otolaryngol 2005; 34: 172-77.

21. Rozanska-Kudelska M, Szulc A, Matulka M, Simonienko K, Rogowski M. Quality of life, depression and anxiety symptoms in patients with chronic rhinosinusitis with polyps treated by endoscopic sinus surgery. Pol Merkur Lekarski 2012; 32: 228-31.

22. Ozkiris M, Kapusuz Z, Saydam L. Comparison of nasal packs with transseptal suturing after nasal septal surgery. Am J Otolaryngol 2013; 34: 308-11.

23. Siegel NS, Gliklich RE, Taghizadeh F, Chang Y. Outcomes of septoplasty. Otolaryngol Head Neck Surg 2000; 122: 228-32.

Received: 19/07/2016

Accepted: 08/12/2016 